\title{
O INVENTÁRIO DOS JARDINS DE BURLE MARX NO RECIFE
}

\section{SÁ CARNEIRO, Ana Rita}

Arquiteta, PhD, prof. do Departamento de Arquitetura e Urbanismo da UFPE, membro do Centro de Estudos Avançados da Conservação Integrada - CECl e coord. do Laboratório da Paisagem da UFPE.

E-mail: anaritacarneiro@hotmail.com

\section{MEDEIROS, Helen M. Palmeira}

Bolsista de iniciação científica e estudante de Arquitetura e Urbanismo pela UFPE.

E-mail: helenpalmeira@yahoo.com.br

COSTA, Eveline Carvalho da

Bolsista de iniciação científica e estudante de Arquitetura e urbanismo pela UFPE.

E-mail: evelineccosta@yahoo.com.br.

\section{RESUMO}

O inventário dos jardins de Burle Marx é parte da pesquisa "A conservação da paisagem cultural como patrimônio natural e construído nas cidades do Nordeste" que vem sendo desenvolvida desde o ano de 2004 no Laboratório da Paisagem da UFPE. O objetivo do inventário é reunir informações sobre os jardins históricos concebidos pelo paisagista visando encaminhar proposta de tombamento nacional como patrimônio cultural e formular diretrizes de conservação. A realização do inventário abre uma nova fase no paisagismo na cidade do Recife porque passa a tratar a praça como jardim, um objeto de valor histórico, artístico e ecológico. As praças são assim objetos de investigação profunda para que sejam demonstrados seus valores culturais na perspectiva do reconhecimento nacional como patrimônio cultural.

Palavras-chave: Inventário, jardim, paisagem.

\begin{abstract}
The Inventory of Burle Marx gardens is part of the research "The conservation of cultural landscape as natural and built heritage in Northeast Brazilian cities" which has carried out in the Landscape Architecture Laboratory of Federal University of Pernambuco since 2004. The aim is to collect data about historical gardens created by the designer Roberto Burle Marx in order to protect them as cultural heritage and to define conservation indicators. The development of the Inventory opens a new stage in the landscape architecture practice in Recife because it considers a square as a garden, an object of historical, artistic and ecological value. These squares are object of detailed research to be demonstrate its cultural values in a view of national recognition as cultural heritage.
\end{abstract}

Key words: Inventory, garden, landscape.

\section{O inventário e o Jardim Histórico}

O jardim é uma das primeiras expressões do homem na sua relação com a natureza. É uma manifestação de ordenação, de construção "artificial" diante do que a paisagem apresenta na sua forma espontânea. É reformar a paisagem natural de acordo com idéias, tendências especificas de pessoas de um determinado lugar caracterizadas pelo seu traço cultural.

A criação de um jardim pode ser interpretada como um gesto na paisagem, como se a expressão humana se aproximasse da arte e da poesia, da "arte de fazer jardins" (Dourado, 1991,p.63). 
Na visão do arquiteto mexicano Raúl Garcia, o jardim é uma das principais representações de toda uma história dos povos e do seu nacionalismo, correspondendo a um produto da evolução da sociedade. É assim entendido como um objeto cultural e também constitui um arquivo vivo que garante a permanência de construções materiais e vegetais (Garcia, 2002).

A conservação de um jardim como um bem cultural pressupõe um estudo da história através de documentos e iconografias para escavar as razões pelas quais foi concebido, assim como os fundamentos formais e funcionais de sua construção e de suas transformações. Sendo assim devem ser levados em conta os contextos: territorial, natural e antrópico, indicando as relações existentes de caráter ecológico entre os componentes arquitetônicos e os componentes naturais. O processo de conservação de um jardim histórico exige disposições teórico-metodológicas de intervenção que começam com a ação de inventariar (Garcia, 2002,p.45-56).

Um inventário constitui assim um instrumento pedagógico de investigação sobre a "arqueologia" dos jardins do ponto de vista de suas características históricas, artísticas e ecológicas. Arqueologia entendida como investigação profunda das diversas camadas de formação que compõe o jardim. O inventário é um registro básico dos sítios culturais e de seus condicionantes, no propósito de auxiliar, nos âmbitos local e nacional, a conservação de seus atributos e o estudo de paisagens culturais, em constante atualização (Alcântara, 2004).

Segundo as diretrizes do Observatori Del Paisatge da Catalunha, o inventário é um instrumento novo para a introdução dos objetivos paisagísticos no planejamento territorial. É um marco conceitual e metodológico que mostra procedimentos básicos para a formulação de políticas de proteção, gestão e de ordenação das paisagens urbanas e de políticas de paisagem. Nesse sentido, o referido órgão está organizando um Catálogo de Paisagens da Catalunha para identificar a tipologia e caracterizar as unidades de paisagens; avaliar as paisagens segundo ameaças e potencialidades; definir os objetivos da conservação com a participação da comunidade e definir os indicadores para a conservação (www.catpaisatge.net/cat/index.php).

Alguns exemplos de inventario foram analisados. A Propuesta de Inventário y Catalogo de Paisajes Culturales y Jardines históricos en México, organizado pelo arquiteto Saul Alcântara Onofre (2004) apresenta uma base conceitual sobre jardins e paisagens históricas, as características das paisagens, a classificação dos valores a serem identificados, além da ficha modelo para cada jardim. Outra proposta que se utilizou como referência foi o Inventario de Espacios Verdes de Buenos Aires - bases conceptuales e ficha modelo, organizado pela arquiteta Sonia Beriman (1997) que assinala a necessidade de lei de proteção para os diferentes tipos de jardins históricos como memória que persiste através do tempo, permanências das projeções dos indivíduos e dos grupos sociais.

Um jardim de interesse histórico é aquele que apresenta aspectos da história da arte das paisagens e dos jardins de um determinado local ou cidade com ênfase nas espécies botânicas e que podem ser exemplos do trabalho de um paisagista em particular que valorize um estilo de projetar. Nessa condição, o jardim histórico está compreendido em uma das três categorias de paisagem cultural firmadas pelo Operational Guidelines for the Implementation of the World Heritage Convention de 1992 (UNESCO). Essa categoria trata das paisagens projetadas e criadas intencionalmente pelo homem que são jardins e parques construídos por razões estéticas.

Com o inventário serão definidos: o valor histórico da paisagem cultural que se baseia no reconhecimento do estado original do sítio e nos fatos associados à história do lugar; o valor artístico que se refere aos condicionantes da concepção do jardim: forma, cor, tempo; o valor ecológico que reside na complementação natureza e cultura para constituir uma identidade cultural e o valor social relacionado ao nível de apropriação por parte dos usuários incluindo sua representação na história do bairro e na legislação urbanística local. Ainda será possível detectar o estado de conservação, relacionado às condições de conservação dos elementos 
materiais - mobiliário, vegetação, etc - e o estado de preservação que relaciona à manutenção da autenticidade, da volumetria, do traçado, etc.

O inventário dos jardins históricos atende às exigências da Carta de Florença, elaborada em 1981 pelo Comitê Internacional de Jardins e Sítios Históricos. Nessa carta a vegetação é considerada o principal elemento da composição paisagística do jardim histórico. Isto o caracteriza como monumento vivo e por isso constitui uma produção arquitetônica que une natureza e cultura. Nesse sentido, o jardim deve ser salvaguardado como testemunho de uma cultura, segundo a Carta de Florença a qual afirma que sua conservação e do seu entorno será garantida através da restauração ou reconstituição e da elaboração de um inventário que o regulará. $\bigcirc$ jardim histórico tem assim um conteúdo simbólico e, portanto, de essência cultural pelas características intrínsecas à sua concepção como objeto artístico, representação de uma época. Essa paisagem cultural encerra um conjunto de atributos que lhe concedem um caráter peculiar relacionando tempo, memória e saber.

No Brasil, o jardim histórico está em fase de definição e ainda não é devidamente compreendido por grande parte dos arquitetos projetistas na sua condição de arquitetura vegetal. Nesse conjunto estão os jardins de Burle Marx, caracterizados pelos princípios do Movimento Moderno e pela busca das raízes nacionais incorporando o passado como fonte de conceitos e informações. É assim que se cristaliza a gênese do jardim brasileiro, materializado em plantas brasileiras e objetos regionais, e levando em conta o tipo de usuário - um novo modo de ver a paisagem. Por isso se justifica o termo jardim aplicado aos espaços livres públicos que priorizam a vegetação como elemento temático de composição artística, em particular 'jardim histórico' como consta na Carta de Florença de 1981. Na concepção de Burle Marx "o jardim é a natureza organizada subordinada às leis arquitetônicas" (Marx, 1935) e ainda "um jardim é o resultado de um arranjo de materiais naturais, obedecendo a leis estéticas e entrelaçado com a visão do artista, sua experiência passada, suas incertezas, aflições, suas tentativas, seus erros e seus sucessos" (Fleming, 1996, p.157). Dessa maneira constitui uma categoria de paisagem cultural que é criada intencionalmente pelo homem por razões estéticas, num trabalho combinado da natureza e do homem e reconhecida em vários países do mundo (UNESCO,1992).

\section{Os jardins de Burle Marx}

A história dos jardins de Burle Marx no Recife começa com as intervenções paisagísticas de expressivo conteúdo artístico que tem início no século XVII no período da ocupação holandesa. O príncipe Maurício de Nassau chegando com uma comitiva de profissionais e artistas construiu - Parque de Friburgo com o palácio de mesmo nome, um parque desenhado por Frans Post contendo alamedas de coqueiros e canteiros de plantas ornamentais e medicinais. Admite-se que esse legado tenha influenciado sua obra artística. Outras influências atribuem-se às espécies vegetais utilizadas nos espaços públicos existentes e à morfologia da paisagem do Recife com a abundância do elemento água.

É no início do século XX, 1934, que mais um momento esplendoroso reacende os valores estéticos da paisagem com a atuação do paisagista Roberto Burle Marx no Setor de Parques e Jardins da Diretoria de Arquitetura e Urbanismo a convite do governo estadual, criando espaços vegetados com fins ecológicos, culturais e sociais, ou seja, jardins temáticos e educativos. São desse momento: a Praça de Casa Forte, a Praça Euclides da Cunha, a Praça do Derby, a Praça da República e o jardim do Campo das Princesas, a Praça do Entroncamento, a Praça Artur Oscar, a Praça Dezessete e a Praça Pinto Damaso (Praça da Várzea). Além dessas praças foi identificado no Arquivo Público o projeto da Praça Barão de Lucena cuja execução ainda não foi confirmada. Esse espaço público desapareceu por conta de ampliação do sistema viário no bairro de Santo Antonio (Fig. 1). 


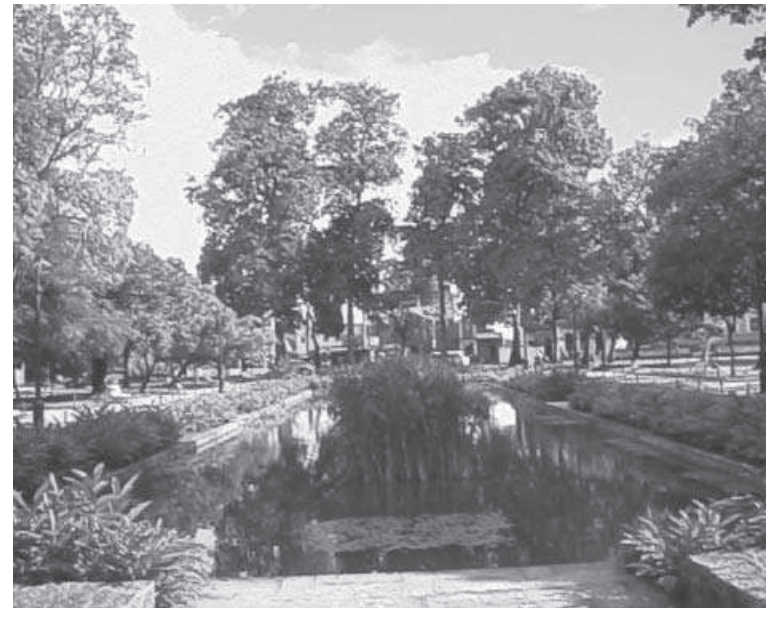

Em 1951, Burle Marx desenha o jardim do entorno da Capela da Jaqueira e no período 1957-58, é novamente convidado para projetar mais dois jardins, um no bairro de Dois Irmãos, a Praça de Dois Irmãos hoje Praça Faria Neves e o outro, em frente ao Aeroporto dos Guararapes, a Praça Salgado Filho, no bairro do Ibura. No conjunto construído do Recife se inserem 11 jardins públicos, na maioria praças, concebidos pelo paisagista Roberto Burle Marx em diferentes bairros. São os primeiros jardins da carreira desse famoso artista, criados em formato de projeto completo ou de projeto de reforma, no intervalo de 1934-37 e, posteriormente, no intervalo de 1957-58 (Fig. 2 e 3).

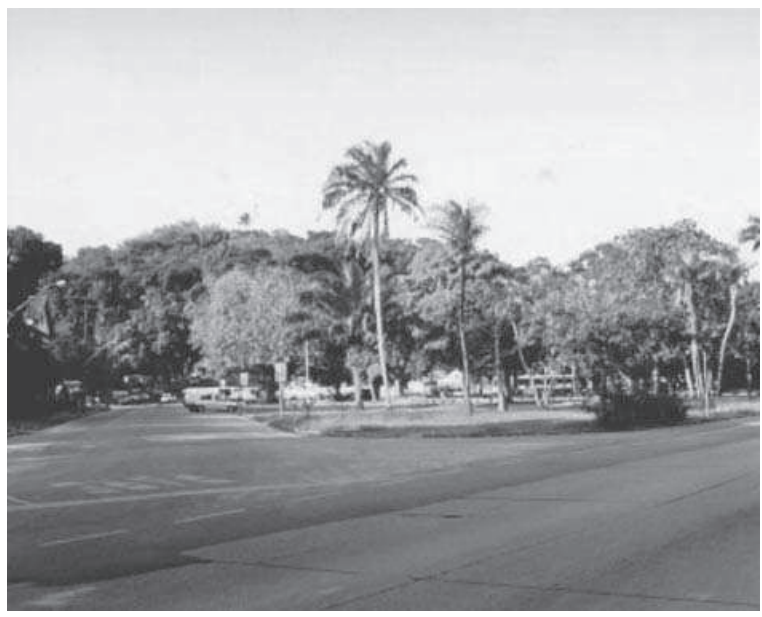

Figura 2: Praça de Dois Irmãos, 2002

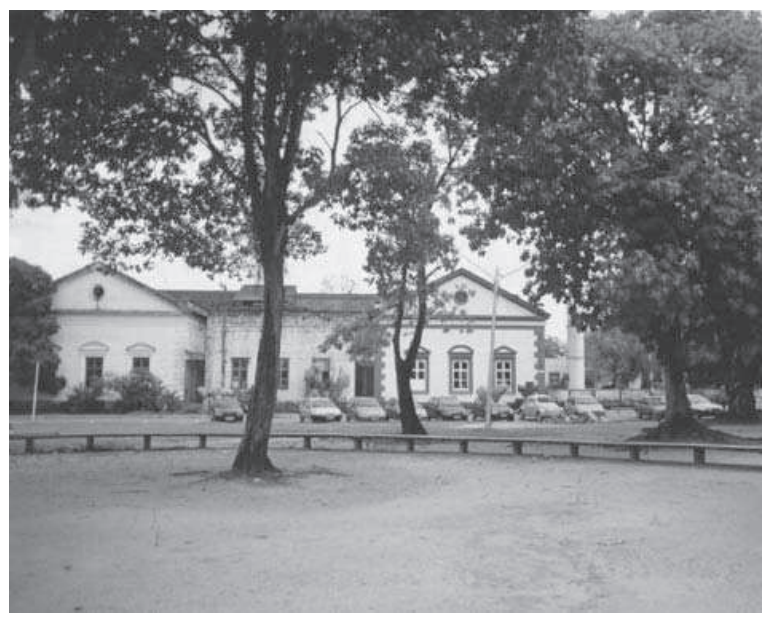

Figura 3: Praça de Dois Irmãos, 2002

A maioria desses jardins ou praças encontra-se em estado de conservação regular; alguns sofreram alterações significativas e estão descaracterizados e há casos de abandono total. Por outro lado, grande parte dos profissionais de arquitetura e a população recifense em geral pouco conhecem da arte dos jardins desse paisagista de renome internacional cujo desempenho local esteve também atrelado a suas origens pernambucanas pelo lado materno.

Os jardins de Burle Marx concebidos segundo princípios artísticos precisam ser protegidos juntamente com o entorno com o qual se relacionam, formal e funcionalmente, das incessantes transformações da construção urbana que ocorrem no Recife. Com isso se pretende conservar a paisagem cultural dos bairros o que certamente estimulará a relação de identidade com os seus habitantes. Tais transformações quase sempre acontecem na perspectiva da renovação em que se prioriza o adensamento construtivo com vistas ao lucro imobiliário e sem a preocupação 
em manter as marcas de uma história de relevante riqueza artística e cultural, enfim, da preservação da memória e identidade dessa cidade que a distingue das demais cidades brasileiras. Dos 11 jardins, foram selecionados oito para a elaboração do inventário e três foram excluídos por se encontrarem descaracterizados. Os jardins selecionados são: Praça de Casa Forte, Praça Euclides da Cunha, Praça do Derby, Praça da República e o jardim do Campo das Princesas, Praça do Entroncamento, Praça Pinto Damaso (Praça da Várzea), Praça Faria Neves (Praça de Dois Irmãos) e Praça Salgado Filho (Praça do Aeroporto) (Fig. 4 e 5).

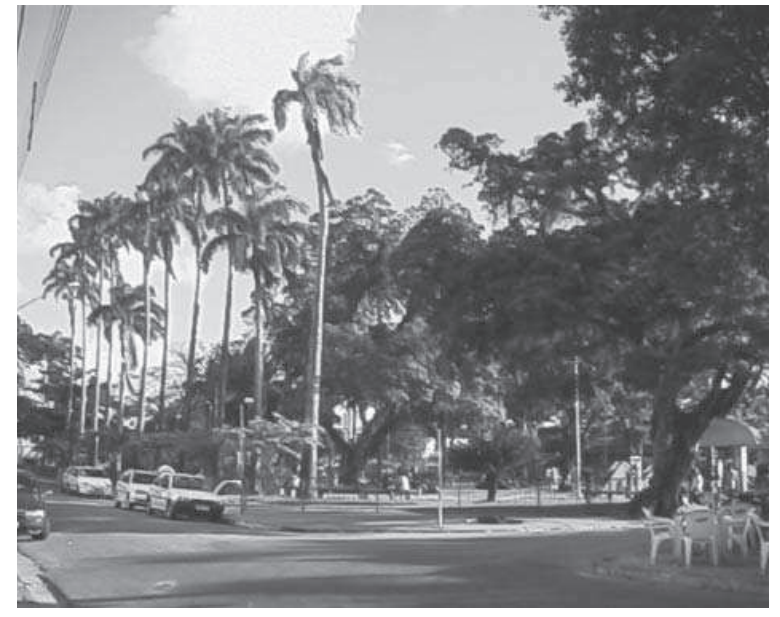

Figura 4: Praça Pinto Damaso, 2004

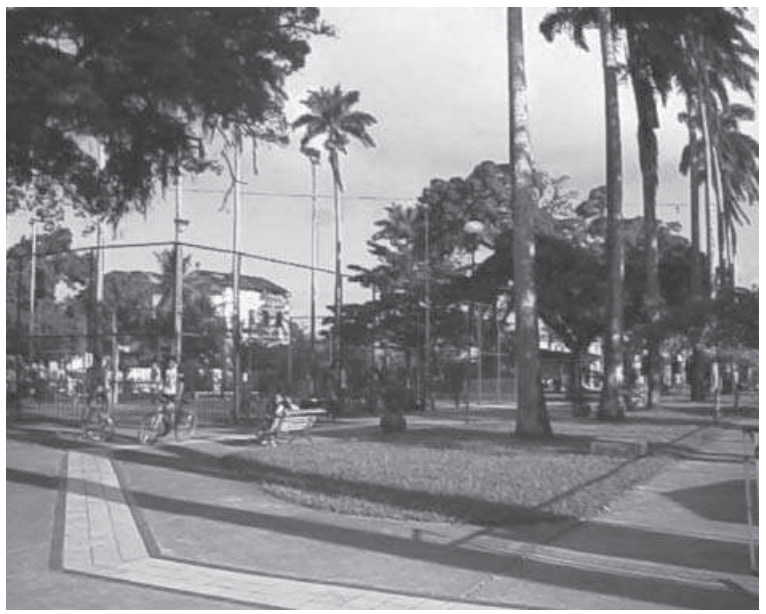

Figura 5: Praça Pinto Damaso, 2004

Portanto, do conjunto de 11 praças foram retiradas a Praça Artur Oscar, a Praça Dezessete e o jardim da Capela da Jaqueira por diferentes motivos. A Praça Artur Oscar e a Praça Dezessete têm hoje características distintas do projeto original e o jardim da Capela está inserido na área do Parque da Jaqueira como parte do sítio histórico.

A proteção legal desses bens irá preservar a memória da cidade garantindo a relação de identidade com os seus habitantes além se funcionar como instrumento educativo para divulgação desse potencial turístico a ser explorado segundo um circuito local de visitação aos jardins de interesse histórico. Informando aos moradores e aos visitantes se assegura uma base sustentável para a cidade, privilegiada pela presença desses jardins de riqueza paisagística, histórica e cultural.

\section{A história dos jardins para o inventário}

Em julho de 2003 teve início a restauração da Praça Euclides da Cunha, um dos primeiros jardins projetados integralmente nos moldes postulados na Carta de Florença de 1981 elaborada pelo Comitê Internacional de Jardins e Sítios Históricos, que é concluída em maio de 2004. Em junho de 2004 essa experiência é apresentada em um encontro nacional de paisagismo na cidade de Belo Horizonte e, em novembro desse mesmo ano, é discutida num encontro internacional sobre conservação urbana realizado no Recife sendo visitada pelo especialista em jardins históricos do Comitê de Jardins Históricos da América Latina, o arquiteto mexicano Saúl Alcântara que atua como consultor desse projeto de inventário. Em junho de 2005 a experiência é novamente apresentada em Conferência Internacional sobre paisagem urbana ocorrida em Gotemburgo, Suécia. Nesse mesmo mês os jardins de Burle Marx no Recife são visitados e fotografados como parte da pesquisa do arquiteto paisagista Christian Tshumi da Dumbarton Oaks, instituição americana de estudos sobre os jardins históricos, estabelecida em Washington. E em novembro de 2005 esses jardins são visitados pelo arquiteto americano Christopher Vernon da University of Western Austrália (Fig. 6 e 7). 


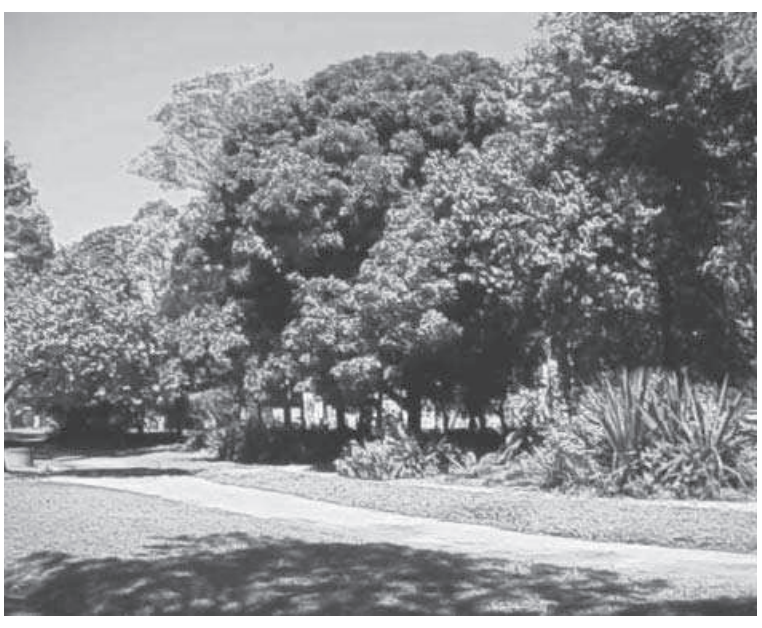

Figura 6: Praça Euclides da Cunha, antes da restauração, 1996

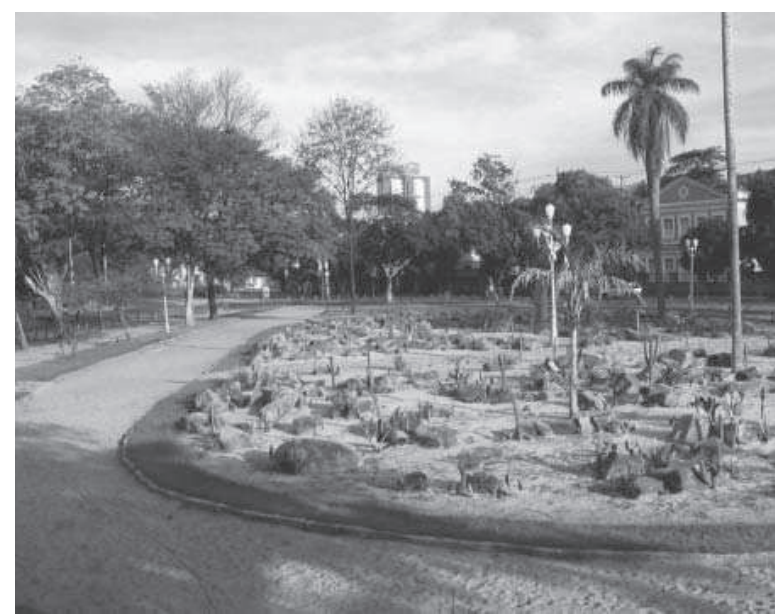

Figura 7: Praça Euclides da Cunha, restaurada, 2004

A Praça Euclides da Cunha é escolhida como exemplo para a elaboração da ficha modelo do inventário porque tinha passado pelo processo recente de restauração ocorrido em 2004. Em seguida estão sendo levantadas as informações dos seguintes jardins: Praça Pinto Damaso ou Praça da Várzea, Praça do Entroncamento e Praça Ministro Salgado Filho ou Praça do Aeroporto.

A ficha modelo elaborada a partir dos exemplos de inventário pesquisados inclui a análise histórica e análise da situação atual e do projeto de restauração como um item complementar. A análise da situação atual está montada em cima de indicadores referentes ao estudo dos elementos arquitetônicos e paisagísticos - edifícios, mobiliário, infra-estrutura, intervenções; estudo do entorno - paradas de ônibus, edifícios, acessos - estudo do meio social - usuários; e estudo botânico.

O levantamento dos projetos originais vem sendo feito no Arquivo Público do Estado de Pernambuco, nos arquivos da Prefeitura do Recife, em museus locais e no Escritório de Burle Marx no Rio de Janeiro. Além disso, uma pesquisa em jornais locais no período entre 1934-1937 e 1957-1958 pretende coletar dados que auxiliem na identificação do traçado e da vegetação além de revelar os princípios adotados pelo paisagista em depoimentos na imprensa daquele momento.

Na perspectiva de investigar o momento de criação de cada praça tem sido relevante fonte de informações a pesquisa nos jornais e revistas locais. As informações apontam fatos curiosos como a utilização dos termos parque, praça e jardim para um mesmo espaço público, encontrados em revista de 1925 e do ano de 1934; a forte preocupação com o embelezamento voltado para a presença de edificações como coretos, fontes, pérgulas e bancos de cimento ornados, até o tipo de arborização das alamedas, e a recuperação e instalação de brinquedos infantis em área cercada e vigiada por funcionário que controlaria o acesso e o uso. Outras observações detectadas tratam de reformas que reduziram a área da praça alterando o traçado na década de 1980 e apropriação de parte da área da praça com comercio informal que aconteceu na Praça da Várzea, em 1995.

Por volta de 1957, notas seguidas do Diário de Pernambuco do mês de agosto destacam um fato que merece reflexão e que está voltado para a consciência paisagística então bem mais exercida do que no momento atual. Trata-se da reivindicação do público quanto à inauguração da Praça do Aeroporto, inclusive expressando a cobrança da presença do paisagista Burle Marx à administração municipal e de informações sobre o projeto que tinha sido anunciado, no qual 
se contemplaria a flora regional do estado. Fica claro o reconhecimento da participação de um técnico de renome como Burle Marx. As noticias mostram também discussão sobre a mudança de monumentos nos espaços públicos e o estado de abandono de outras praças.

Uma reportagem do Boletim Técnico da Secretaria de Viação e Obras Públicas (volume XLVIII, de out a dez) de 1957, destaca que o Departamento do Bem Estar Público do Governo Estadual construiu um magnífico jardim na Estação de Passageiros do Aeroporto dos Guararapes projetado pelo arquiteto-paisagista Burle Marx que tinha no centro um lago em torno do qual estão dispostas belas massas de vegetação mostrando a flora de Pernambuco. Uma grande reportagem de 7/08/1957 ressalta o reencontro de Burle Marx com suas obras dos anos de 1930, e uma descrição do Jardim da Capela da Jaqueira, concebido em 1951, para valorizar a arquitetura da capela. Além disso, fala dos seus projetos no Brasil e na Venezuela.

Essas informações coletadas nos arquivos sobre os jardins de Burle Marx tem servido para elucidar dúvidas a respeito do traçado e da vegetação indicadas pelo paisagista porque alguns dos projetos originais não foram encontrados. O conteúdo que está sendo descoberto e aos poucos divulgados vem elevando o nível das intervenções paisagísticas com a restauração da Praça Euclides da Cunha em 2004 e o inicio das obras de restauração da Praça de Dois Irmãos nesse mês de abril de 2006.

\section{Bibliografia}

ALCÂNTARA, Saul; PEREZ, E.; SÁNCHEZ, Félix. Diseño, planificación y conservación de paisajes y jardines. 2002. Posgrado: (Epecialzación y Maestria em Diseño) - Universidad Autônoma Metropolitana, México: Limusa Noriega Editores, 2002.

ALCÂNTARA, Saúl. Plan Maestro para la Recuperación Monumental y Ambiental de la Huerta Histórica del Museo Nacional del Virreinato, Tepotzotlán, Estado de México, Metodologia del Proyecto de Recuperacion, 2000.

Paisajes y jardines históricos en México. Conocimiento, tutela y puesta en valor. Casos de Estudio, 2004.

. Propuesta de inventario y catálogo de paisajes culturales y jardines históricos em México, 2004.

BERJMAN, Sonia. Inventario de espacios verdes. Bases conceptuales y ficha modelo. Buenos Aires: Facultad de Agronomia da Universidad de Buenos Aires, 1997.

CURY, Isabelle. Cartas patrimoniais. Iphan. Rio de Janeiro: Edições do Patrimônio, 2000.

DELPHIM, Carlos de Moura. Manual de intervenções em jardins históricos. Rio de Janeiro, 2004.

DOURADO, Guilherme Mazza. Burle Marx. O prazer de viver e trabalhar com a natureza. Revista Projeto, São Paulo, n. 146, p. 58-77, 1991.

FLEMING, Laurence. Roberto Burle Marx, um retrato. Rio de Janeiro: Index, 1996.

GARCIA, Raúl Raya. Conceptos de conservación de paisajes y jardines. In: ONOFRE, Saúl Alcântara et al. Diseño, planificación e conservación de paisajes y jardines. México: Limusa Noriega Editores, 2002.

MARX, Roberto Burle. Jardins para Recife. Boletim de Engenharia, Recife, Ano XIII, v. VII, 1935.

REALIZAÇÕES da Prefeitura do Recife no exercício de 1957: Informação do Departamento de Documentação e Cultura, enviada pelo seu diretor e dr. José Césio Regueira Costa. Boletim técnico da Secretaria de Viação e Obras Públicas. Recife: Administração do Porto do Recife, ano XIX, v. XLVIII, p. 16-17, 1957.

UNESCO. Operational guidelines for the implementation of the world convention, 1992.

UNIVERSITY OF YORK. Survey and inventory. Centre for the conservation of historic parks and gardens. 
